\title{
Evaluation of Several New Models to Teach English as a Second Language
}

\author{
http://dx.doi.org/10.3991/ijet.v11i08.6037 \\ Jian Wang \\ Zaozhuang University, Zaozhuang, China
}

\begin{abstract}
With the development of modern society, it is commonly accepted in China that English as a second language has attracted much attention especially for students. How to select an appropriate model to learn English is still an important question. After the induction of some relevant attributes related to the assessment of this problem, the key point is to propose a method to assess different models, which can be considered as a MADM problem. To date, many attempts by researchers have been done, but there are still some drawbacks. Thus, in order to overcome the weakness in existing methods, an intuitionsitic fuzzy multiple decision making method is proposed in this paper to acquire an optimal model including the construction of a decision matrix, aggregation operators, score function and a method for determining the weights of attributes. Finally, an example is demonstrated to verify the applicability of the method proposed in this paper.
\end{abstract}

Index Terms-English education, Intuitionistic fuzzy information, Multiple attributes decision making. Aggregation operators

\section{INTRODUCTION}

It is widely accepted that language education is a key field in all education fields all over the world. English, as the most widely used language globally, has attracted increasing attention [1-2]. The global spread of English has reshaped the sociolinguistic realities of the language, which has lead to the emergence of a number of local English varietiations in different places of the world [3]. In general, social cultural theory indicates the interdependence of social and individual processes in the development of human cognition. Learning happens in a cultural environment which is mediated by artifacts such as language, other symbolic systems, and humans [4]. During the learning process, humans use culturally created concepts and activities to regulate the material world of their own and each other's social and mental activity. Thus, students as a typical representation of humans in modern society, need to learn language including a second language such as English using the strength of culture [56]. But this is only one factor to learn a language well. How to help students master the second language is still a question and attract many researchers' attention [7-10]. To date, many research projects have attemptemted to do so.

Vygotsky (1978) argued that language is the most powerful tool that mediates learner development. Since language is the medium through which learners develop and internalize knowledge, then it is arguably correct to suggest that language is fundamental to effective learning [11]. Swain (2010) presented a thorough analysis of the ongoing process of cognitive change triggered by verbalization. They used genetic analysis to analyze the language performance of a high and low level language learner drawn from a sample of nine university learners of French in their original study [12]. Kirkpatrick (2006) proposed a localized model which is culturally, politically and linguistically more relevant to teachers and learners in that context than a native speaker model [13].

In China, English as a second language has been a significant aspect of this study. English proficiency has long been promoted as indispensable for the nation's modernization and internationalization, although English is seldom used for daily communication. English language education has been a compulsory course in mainstream education from primary schools to universities. How to select a perfect learning model or teaching model is an important question to help students promote English learning. There are many attributes to help this selection, which can be considered a MADM problem. Some experts can be invited to provide assessments on different attributes, but it is difficult to obtain the preferences of experts exactly. Many ways have been introduced in this field such as interval numbers, triangular numbers, and especially fuzzy numbers [14-18].

Intuitionistic fuzzy numbers [19-20], as the major aspect of fuzzy numbers, are introduced in this paper to help express the preferences of the decision maker or expert. Here, after construction of the decision matrix, aggregation operators are proposed in this paper to aggregate the information in the decision matrix with intuitionisitc fuzzy numbers. In general, there are three basic types of aggregation operators with fuzzy information including operators for the intersection of fuzzy sets (e.g. the Min operator), operators for the union of fuzzy sets (e.g. the Max operator) and averaging operators [21-23]. Combining with the advantages of the mentioned operators, the ordered weighted averaging (OWA) operator is developed in this paper. Then, a score function is also proposed to rank different alternatives. Based on these methods, an appropriate teaching model can be selected. Finally, an example is demonstrated to verify the applicability of the method proposed in this paper.

The rest of this paper is organized as follows. In Section 2 , some concepts of intuitionistic fuzzy sets are reviewed, such as the definition of intuitionsitc fuzzy sets and the operational laws. Section 3 proposes a new method including the ordered weighted averaging operator with intuitionistic fuzzy numbers. An example is demonstrated in Section 4 to verify the applicability of this method. Finally, Section 5 concludes this paper. 


\section{PRELIMINARY}

In this section, some concepts of intuitionistic fuzzy sets are introduced to deal with multiple criteria decision making problem such as assessment of performance of cloud computing in education.

Definition 1. Let $X$ be a universe of discourse, then a fuzzy set is defined as:

$$
A=\left\{\left\langle x, u_{A}(x)\right\rangle \mid x \in X\right\}
$$

which is characterized by a membership function $u_{A}: X \rightarrow[0,1]$, where $u_{A}$ denotes the degree of membership of the element $x$ to the set $A$.

Definition 2. Let $X$ be an ordinary finite non-empty set. An intuitionisitc fuzzy set in $X$ is an expression $A$ given by

$$
A=\left\{\left\langle x, u_{A}(x), v_{A}(x)\right\rangle \mid x \in X\right\}
$$

where, $u_{A}: X \rightarrow[0,1]$ denotes the degree of membership and $v_{A}: X \rightarrow[0,1]$ denotes the degree of non-membership with the condition: $0 \leq u_{A}+v_{A} \leq 1$, for all elements $x$ in the set $X$.

For each intuitionistic fuzzy set $A$ in $X$, if the amount

$$
\pi_{A}(x)=1-u_{A}(x)-v_{A}(x), \forall x \in X .
$$

Then $\pi_{A}(x)$ is referred to as the degree of indeterminacy of the element $x$ to the set $A$. Especially, if

$$
\pi_{A}(x)=1-u_{A}(x)-v_{A}(x)=0, \forall x \in X .
$$

Thus, the intuitionisitc fuzzy set is reduced to a fuzzy set. For computational convenience, in this paper, $\left(u_{A}(x)\right.$, $\left.v_{A}(x)\right)$ is referred to as an intuitionistic fuzzy number.

Definition 3.[19] Let $a=\left(u_{a}, v_{a}\right)$ and $b=\left(u_{b}, v_{b}\right)$ be two intuitionistic fuzzy numbers, then it can be obtained that

(1) $a \oplus b=\left(u_{a}+u_{b}-u_{a} u_{b}, v_{a} v_{b}\right)$;

(2) $a \otimes b=\left(u_{a} u_{b}, v_{a}+v_{b}-v_{a} v_{b}\right)$;

(3) $\lambda a=\left(1-\left(1-u_{a}\right)^{\lambda},\left(v_{a}\right)^{\lambda}\right), \lambda>0$;

(4) $a^{\lambda}=\left(\left(u_{a}\right)^{\lambda}, 1-\left(1-v_{a}\right)^{\lambda}\right), \lambda>0$.

Definition 4.[19] Given two intuitionistic fuzzy values $A$ and $B$, the following operations are valid:

(1) $a \oplus b=b \oplus a$;

(2) $\lambda_{1}(a \oplus b)=\lambda_{1} a \oplus \lambda_{1} b$;

(3) $\lambda_{1} a \oplus \lambda_{2} a=\left(\lambda_{1}+\lambda_{2}\right) a$.

\section{Proposed Method To Assess The SEVERAL NEW MODELS}

In this section, a new method is proposed in the context of the introduction of some teaching models to select an appropriate one.

\section{A. The introduction of several new teaching models}

Many efforts have resulted in a growing number of diverse English as a Second language for students in China. The challenges students face related to language barriers are not only evident in China, but in other Englishspeaking countries as well. These students often have limited English proficiency, which can result in language

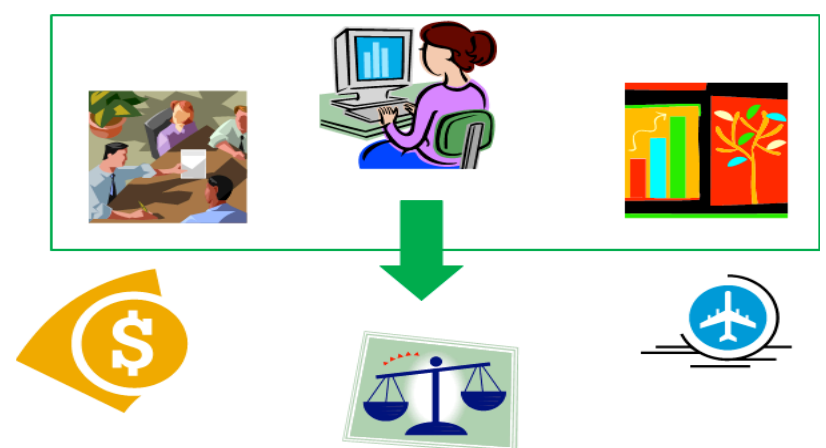

Figure 1. The basic relationship of new models

and cultural barriers that impede their success in China. Students have been found to have higher rates of attrition and lower levels of academic achievement.

Now, many new models have been developed to teach and train students to learn English, including on-line, offline and using a mobile device. Then, the most important issue is how to choose the most appropriate and effective method. Therefore, how to assess these models is a significant problem. In order to solve this problem, many evaluation attributes have been proposed to help the decision making process select the optimal alternative.

\section{B. The method to aggregation information}

The most important thing to assess alternatives is to aggregate information of these alternatives. Operators are a direct way of aggregation of information. To date, many operators have been proposed with fuzzy information, especially intuitionistic fuzzy information.

Two of the most common operators for aggregating arguments are the weighted averaging operator and the ordered weighted averaging operators, respectively.

First of all, the weighted averaging operator with intuitionistic fuzzy numbers will be introduced.

Definition 5. Let $a_{j}=\left[u_{j}, v_{j}\right](j=1,2, \ldots, n)$ be a collection of intuitionistic fuzzy numbers, then their aggregation of intuitionistic fuzzy numbers can be defined using the following intuitionistic fuzzy weighted operators:

$$
\begin{aligned}
& \operatorname{IFWA}\left(a_{1}, a_{2}, \ldots, a_{n}\right)=\sum_{j=1}^{n} w_{j} a_{j} \\
& =w_{1} a_{1} \oplus w_{2} a_{2} \oplus \ldots \oplus w_{n} a_{n},
\end{aligned}
$$$$
\text { (2) }
$$

where $w=\left(w_{1}, w_{2}, \ldots, w_{n}\right)^{\mathrm{T}}$ is the weight vector of $a_{j}(j=$ $1,2, \ldots, n)$. with $w_{\mathrm{j}} \in[0,1]$ and $\sum_{j=1}^{n} w_{j}=1$.

In Eq. (2), if $w=(1 / n, 1 / n, \ldots, 1 / n)^{\mathrm{T}}$, then IFWA operator is reduced to an intuitionistic fuzzy averaging (IFA) operator of dimension $n$, which is defined as follows:

(3)

$$
\operatorname{IFWA}\left(a_{1}, \quad a_{2}, \quad \ldots, \quad a_{n}\right)=\frac{1}{n}\left(a_{1} \oplus a_{2} \oplus \ldots \oplus a_{n}\right) .
$$

Based on the above mentioned definition, the following new operation can be obtained.

$\operatorname{IFWA}\left(a_{1}, a_{2}, \ldots, a_{n}\right)=$

$$
\left[1-\prod_{j=1}^{n}\left(1-u_{a_{j}}\right)^{w_{j}}, 1-\prod_{j=1}^{n}\left(v_{a_{j}}\right)^{w_{j}}\right] .
$$


Additionally, there is another important operator named the ordered weighted averaging (OWA) operator, which can reflect the common characteristic of the existing operators with fuzzy information.

Definition 6. Let $a_{j}=\left[u_{j}, v_{j}\right](j=1,2, \ldots, n)$ be a collection of intuitionistic fuzzy numbers, then their aggregation of intuitionistic fuzzy numbers can be defined using the following intuitionistic fuzzy ordered weighted operators:

$$
\begin{aligned}
& \operatorname{IFOWA}\left(a_{1}, a_{2}, \ldots, a_{n}\right)=\sum_{j=1}^{n} \omega_{j} a_{\sigma(j)} \\
& =\quad \omega_{1} a_{\sigma(1)} \oplus \omega_{2} b_{\sigma(2)} \oplus \ldots \oplus \omega_{n} b_{\sigma(n)} \quad,
\end{aligned}
$$

where $a_{\sigma(j)}$ is the $j$ th largest element in the set of inputs $\left\{a_{j}\right\}$ which are assumed to belong to the unit interval and $(\sigma(1), \sigma(2), \ldots, \sigma(n))$ is a permutation of $(1,2, \ldots, n)$, such that $a_{\sigma(j-1)} \geq a_{\sigma(j)}$ for all $j . \omega_{j}$, as the balance coefficients are the order of weights such as $\omega_{j} \square[0,1]$ and $\sum_{j=1}^{n} \omega_{j}=1$.

Similarly, the following can be obtained:

$\operatorname{IFOWA}\left(a_{1}, a_{2}, \ldots, a_{n}\right)$

$$
=\left[1-\prod_{j=1}^{n}\left(1-u_{a_{\sigma(j)}}\right)^{\omega_{j}}, 1-\prod_{j=1}^{n}\left(v_{a_{\sigma(j)}}\right)^{\omega_{j}}\right] \text {. }
$$

Here, if $\omega=(1 / n, 1 / n, \ldots, 1 / n)^{\mathrm{T}}$, then the IFOWA operator is reduced to an intuitionistic fuzzy averaging (IFA) operator of dimension $n$.

In addition, if intuitionistic fuzzy sets are reduced to fuzzy sets, then Eq. (6) will be reduced to the following equation:

$$
\operatorname{IFOWA}\left(a_{1}, a_{2}, \ldots, a_{n}\right)=1-\prod_{j=1}^{n}\left(1-u_{a_{\sigma(j)}}\right)^{\omega_{j}} .
$$

Compared with other operators, IFOWA satisfies the following condition:

$\operatorname{IF}_{\text {Min }}\left(a_{1}, a_{2}, \ldots, a_{n}\right) \leq \operatorname{IFOWA}\left(a_{1}, a_{2}, \ldots, a_{n}\right) \leq \operatorname{IF}_{\text {Max }}\left(a_{1}\right.$, $\left.a_{2}, \ldots, a_{n}\right)$.

\section{The way to rank models}

The order of weights depends on the decision maker's degree of optimism which is known as the Orness degree. If the weights at the beginning of the weight vector become larger, then the degree of optimism to accept risk of the decision maker will become larger. According to the weights for the OWA operator, the degree of optimism $\theta$ is defined as follows:

$$
\theta=\frac{1}{n-1} \sum_{j=1}^{n}(n-j) \omega_{j}
$$

The three major states of $\theta$ include the optimistic views, the neutral and the pessimistic views of the decision maker.

Many methods have been proposed to determine the order of weights. One of the most frequently used methods is based on the fuzzy linguistic quantifiers. In natural languages some linguistic terms such as most, few, many and about half are often applied. Zadeh (1983) called them linguistic quantifiers and suggested to model these linguistic quantifiers by fuzzy sets.
Regular Increasing Monotonic (RIM) quantifiers Q as one of the linguistic quantifiers are introduced in this paper. Here, the more objects that are included, the higher the satisfaction is. That is, $Q\left(r_{1}\right) \geq Q\left(r_{2}\right)$ as $r_{1} \geq r_{2}$.

Based on this, Yager (1988) provided that

$$
\begin{aligned}
& \operatorname{IFOWA}\left(a_{1}, a_{2}, \ldots, a_{n}\right)=\sum_{j=1}^{n} \omega_{j} a_{\sigma(j)} \\
& =\sum_{j=1}^{k} \omega_{j}=S_{k} \\
& \text { where } j \leq k \text { and } a_{\sigma(j)}=0 \text { for } j>k .
\end{aligned}
$$

Thus $S_{k}$ is the satisfaction degree of the decision maker for the $k / n$ portion of the criteria. The marginal satisfaction is defined as the weight of satisfying only one criterion in that order, or $\omega_{j}=S_{j}-S_{j-1}$. Then, a better model is constructed by Yager to obtain the weights of an $n$-dimension OWA operator as follows:

$$
\omega_{j}=Q\left(\frac{j}{n}\right)-Q\left(\frac{j-1}{n}\right), j=1,2, \ldots, n .
$$

The type of the RIM quantifiers can be obtained in questioning the decision maker as to how many criteria the decision maker considers. The decision maker's degree of optimism can be calculated by using these quantifiers. The relation for RIM quantifiers can be derived from the following:

$$
\theta=\int_{0}^{1} Q(r) d r
$$

After aggregation of intuitionsitic fuzzy information, the critical step is to rank different intuitionistic fuzzy numbers according to score function and accuracy function.

Definition 7. Let $a=[u, v]$ be an intuitionistic fuzzy number. The score function of $a$ can be obtained as follows:

$$
S(a)=u_{a}-v_{a}
$$

Definition 8. Let $a=[u, v]$ be an intuitionistic fuzzy number. The accuracy function of $a$ can be obtained as follows:

$$
H(a)=u_{a}+v_{a}
$$

Definition 9. For two intuitionistic fuzzy numbers $a_{1}$ and $a_{2}$, some rules can be obtained to compare them as follows:

if $S\left(a_{1}\right)>S\left(a_{2}\right)$, then $a_{1}$ is better than or preferred to $a_{2}$, denoted by $a_{1}>a_{2}$;

if $S\left(a_{1}\right)=S\left(a_{2}\right)$, then

if $H\left(a_{1}\right)>H\left(a_{2}\right), a_{1}$ is better than or preferred to $a_{2}$, denoted by $a_{1}>a_{2}$;

if $H\left(a_{1}\right)=H\left(a_{2}\right), a_{1}$ is indifferent to $a_{2}$, denoted by $a_{1}$ $=a_{2}$;

if $H\left(a_{1}\right)<H\left(a_{2}\right), a_{2}$ is better than or preferred to $a_{1}$, denoted by $a_{1}<a_{2}$.

These rules will be applied in the following section.

\section{Decision procedure}

In this section, a procedure to form this evaluation model based on the above mentioned methods is proposed including the following steps: 
Step1. For an evaluation problem, a decision matrix is constructed $A=\left[a_{i j}\right]_{m ¥ n}$, where all the arguments $a_{i j}(i=1$, $2, \ldots, m ; j=1,2, \ldots, n)$ are intuitionistic fuzzy numbers, given by the decision maker. As for every alternative $A_{i}(i$ $=1,2, \ldots, m)$, the decision maker is invited to express an evaluation or preference according to each attribute $C_{j}(j=$ $1,2, \ldots, n)$. Then, a normal decision making matrix can be obtained as follows:

$$
A_{m \times n}=\left(\begin{array}{cccc}
a_{11} & a_{12} & \mathrm{~L} & a_{1 n} \\
a_{21} & a_{22} & \mathrm{~L} & a_{2 n} \\
\mathrm{M} & \mathrm{M} & \mathrm{O} & \mathrm{M} \\
a_{m 1} & a_{m 2} & \mathrm{~L} & a_{m n}
\end{array}\right)
$$

Step 2. The decision maker specifies the order weights of the $n$ attributes denoted as $\omega=\left(\omega_{1}, \omega_{2}, \ldots, \omega_{n}\right)^{T}$ with $0 \leq \omega_{j} \leq 1(j=1,2, \ldots, n)$ and $\sum_{i=1}^{n} \omega_{j}=1$. Then, based on the risk preference of the decision maker and Eq. (10), the order weights can be acquired.

Step 3.The intuitionistic fuzzy ordered weighted operators (IFOWA) denoted as Eq.(5) are introduced to aggregate the intuitionistic fuzzy assessments. Then, the aggregation results of each alternative can be obtained.

Step 4. The score function and accuracy function are used to compare each alternative in the decision making matrix.

Step 5. Through different score and accuracy value of alternatives, the rank-order can be obtained. Then, the optimal alternative can be selected by the largest values.

\section{ILLUSTRATIVE EXAMPLE}

In this section, the selection problem about teaching models will be solved by the proposed method in this paper.

Using the basic relationship between the three models in Figure 1, a new attribute system can be obtained as shown in Figure 2. This means that the three teaching models are on-line denoted by $A_{1}$, off-line denoted by $A_{2}$ and mobile device denoted by $A_{3}$. Meanwhile, five attributes are demonstrated as quality denoted by $C_{1}$, satisfaction denoted by $C_{2}$, brand denoted by $C_{3}$, cost denoted by $C_{4}$ and peer evaluation denoted by $C_{5}$. A famous expert was invited to act as the decision maker to provide the assessments of each model on each attribute so as to help others select an appropriate model. As mentioned above,

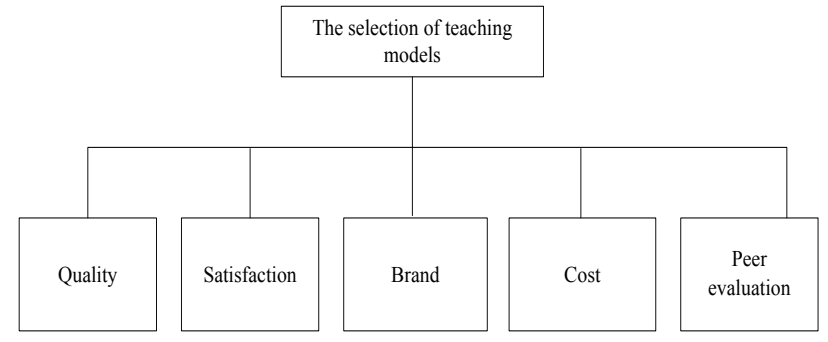

Figure 2. A new attribute system

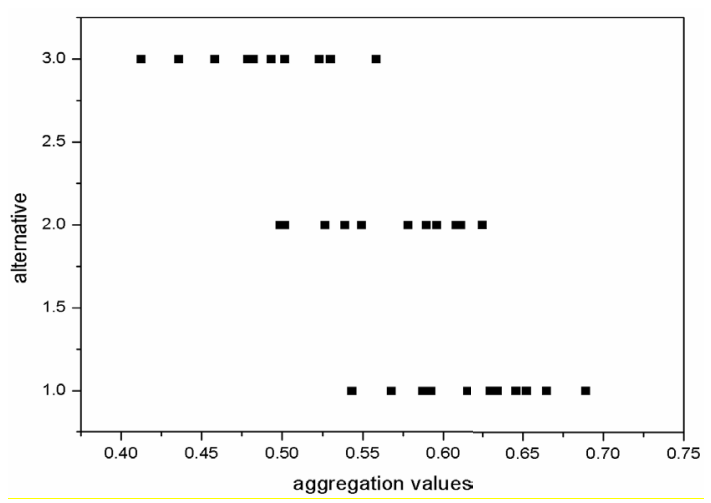

Figure 3. The aggregation result of each alternative

the decision maker finds it difficult to express exact preferences, so the intuitionistic fuzzy numbers are introduced to help the decision maker provide preferences of each alternative on each attribute, respectively. Then, the decision matrix with intuitionistic fuzzy numbers denoted

by $D=\left[a_{i j}\right]_{4 ¥ 3}$ can be demonstrated in Table 1. Here, the decision maker gives an assessment of a model on an attribute without consideration of other attributes. That is, the attributes in the decision matrix are mutually independent.

Based on the decision matrix, the decision maker uses Eq. (10) to obtain the order weights of each alternative as $\{0.3,0.25,0.25,0.1,0.1\}$. Then, the intuitionistic fuzzy ordered weighted operators are introduced to aggregate the intuitionsitc fuzzy information of each alternative on each attribute in Figure 3. In addition, score and accuracy value of alternative are computed by Eqs. (12) - (13). Finally, based on the rules in Definition 9, we can obtain the ranking order of alternatives can be obtained as shown in Table 2. From this ranking order, $A_{1}$ can be selected as the best choice.

TABLE I. INTUITIONISTIC FUZZY DECISION MATRIX

\begin{tabular}{|c|c|c|c|c|c|}
\hline & $C_{1}$ & $C_{2}$ & $C_{3}$ & $C_{4}$ & $C_{5}$ \\
\hline$A_{1}$ & $\{0.6,0.2,0.2\}$ & $\{0.7,0.1,0.2\}$ & $\{0.7,0.2,0.1\}$ & $\{0.8,0.1,0.1\}$ & $\{0.5,0.2,0.3\}$ \\
\hline$A_{2}$ & $\{0.8,0.1,0.1\}$ & $\{0.6,0.3,0.1\}$ & $\{0.6,0.1,0.3\}$ & $\{0.5,0.1,0.4\}$ & $\{0.7,0.2,0.1\}$ \\
\hline$A_{3}$ & $\{0.5,0.3,0.2\}$ & $\{0.5,0.5\}$ & $\{0.6,0.3,0.1\}$ & $\{0.7,0.2,0.1\}$ & $\{0.6,0.3,0.1\}$ \\
\hline
\end{tabular}

TABLE II. THE RANKING ORDER

\begin{tabular}{|c|c|c|}
\hline & score & rank \\
\hline$A_{1}$ & 0.6414 & 1 \\
\hline$A_{2}$ & 0.5929 & 2 \\
\hline$A_{3}$ & 0.5174 & 3 \\
\hline
\end{tabular}




\section{CONCLUSIONS}

It is widely accepted that language education is a key field in all education fields all over the world. English, as the most widely used language globally, has increasingly attracted attention. The global spread of English has been reshaping the sociolinguistic realities of the language, which has lead to the emergence of a number of local English varieties in different areas of the world. In China, English as an important second language has been a significant aspect of our study. English proficiency has long been promoted as indispensable for the nation's modernization and internationalization though English is seldom used for daily communication in Chinese people's daily lives. in order to overcome the weakness in existing methods, an intuitionsitic fuzzy multiple decision making method is proposed in this paper to acquire an optimal model including the construction of a decision matrix, aggregation operators, score function and a method for determining the weights of attributes. Finally, an example is demonstrated to verify the applicability of the method proposed in this paper.

\section{REFERENCES}

[1] W. H. Wang. Teaching English as an international language in China: Investigating university teachers' and students' attitudes towards China English, System, 53 (2015) 60-72. http://dx.doi.org/10.1016/j.system.2015.06.008

[2] K. Bolton, Chinese English: A sociolinguistic history. Cambridge: Cambridge University Press. (2003).

[3] T. Chakraborty, S. K. Bakshi, English language premium: Evidence from a policy experiment in India. Economics of Education Review, (50) (2016) 1-16. http://dx.doi.org/10.1016/j.econedurev. 2015.10.004

[4] M. Azam, A. Chin, N. Prakash, The returns to English-language skills in India, Economic Development and Cultural Change, 61 (2), (2013) 548-579. http://dx.doi.org/10.1086/668277

[5] F. Dustmann, F. Fabbri, Language proficiency and labour market performance of immigrants in the UK. Economic Journal, 113(489), (2003) 695-717. http://dx.doi.org/10.1111/14680297.t01-1-00151

[6] R. Guha, The question of English-worldwide, English remains the choice of communication, The telegraph, Calcutta, India (2011).

[7] G. Eksi, B. Y. Yakisk, An investigation of prospective English language teachers' multimodal literacy, An international conference on teaching and learning English as an additional language, Antalya-Turkey, 199 (2015) 464-471.

[8] W. C. Sewell, S. Denton, Multimodal literacies in the secondary English classroom. English Journal. 100(5) (2011) 61-65.

[9] X. Q. Hu, Why China English should stand alongside British, American, and the other World Englishes, English Today, 20(2) (2004) 26-33. http://dx.doi.org/10.1017/S0266078404002056
[10] D. Nunan, The impact of English as a global language on educational policies and practices in the Asia-Pacific Region. TESOL Quarterly, 37(4) (2003) 589-613. http://dx.doi.org/10.2307/ 3588214

[11] L. S. Vygotsky, Mind in society. Chmbridge: MA: Harvard University Press, (1978).

[12] M. Swain, P. Kinner, L. Steinman, Sociocultural theory in second language: An introduction through narratives. Ontario: Multilingual Matters, (2010).

[13] A. Kirkpatrick, Which models of English: native-speaker, nativized or lingua franca? English in the world: Global rules, global roles, London: Continuum.71-83.

[14] P. J. F. Groenen, K. Jajuga, Fuzzy clustering with squared Minkowski distance, Fuzzy Sets and Syste,s, 120 (2001) 227-237.

[15] C. C. Chou, The canonical representation of multiplication operation on triangular fuzzy numbers, Computer Mathematic Application, 45 (2003) 1601-1610. http://dx.doi.org/10.1016/S08981221(03)00139-1

[16] A. Kaufmann, M. M. Gupta, Introduction to fuzzy arithmetic: theory and applications, Van Norstrand Reinhold, (1985) New York.

[17] C. Labreuche, M. Grabisch, The Choquet integral for the aggregation of interval scales in multicriteria decision making, Fuzzy Sets and Systems, 137 (2003) 11-26. http://dx.doi.org/10.1016/S01650114(02)00429-3

[18] D. H. Hong, C. H. Choi, Multicriteria fuzzy problems based on vague set theory, Fuzzy Sets and Systems 114 (2000) 103-113. http://dx.doi.org/10.1016/S0165-0114(98)00271-1

[19] Z. S. Xu, Intuitionistic fuzzy aggregation operators. IEEE Transaction on Fuzzy Systems, 15 (2007) 1179-1187. http://dx.doi.org/10.1109/TFUZZ.2006.890678

[20] P. Balasubramaniam, V. P. Ananthi, Image fusion using intuitionistic fuzzy sets, Information fusion, 2014 http://dx.doi.org/10.1016/j.inffus.2013.10.011

[21] C.Q. Tan, X.H. Chen, Intuitionisic fuzzy Choquet integral operator for multi-criteria decision making, Expert Systems with Applications, 37 (2010) 149-157. http://dx.doi.org/10.1016/j.eswa. 2009.05.005

[22] R. R. Yager, On the dispersion measure of OWA operators, Information Sciences, 179 (2009) 3908-3919.

[23] R. Fuller, P. Majlender, An analytic approach for obtaining maximal entropy OWA operator weights, Fuzzy sets and Systems, 124 (2001) 53-57. http://dx.doi.org/10.1016/S0165-0114(01)00007-0

\section{AUTHOR}

Jian Wang is a lecturer in the Department of College English, Zaozhuang University, Zaozhuang, 277160, China. His research interests include English teaching appraisal, online education and CAT. (warm@msn.cn)

Submitted 16 July 2016. Published as resubmitted by the authors 18 August 2016. 